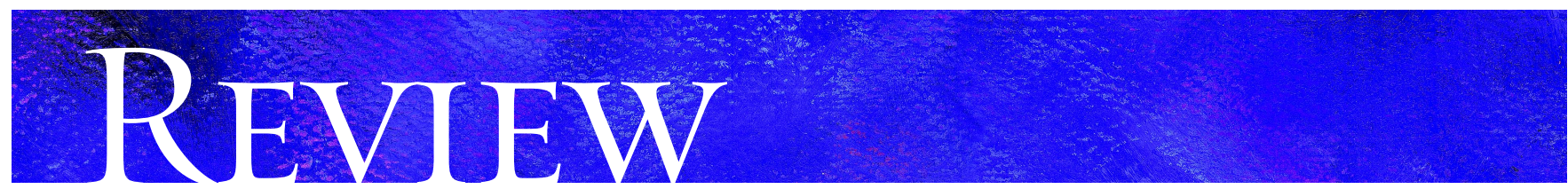

\title{
Diet in the management of weight loss
}

\author{
Irene Strychar
}

\section{ABSTRACT}

Obesity is an established risk factor for numerous chronic diseases, and successful treatment will have an important impact on medical resources utilization, health care costs, and patient quality of life. With over $60 \%$ of our population being overweight, physicians face a major challenge in assisting patients in the process of weight loss and weight-loss maintenance. Low-calorie diets can lower total body weight by an average of $8 \%$ in the short term. These diets are welltolerated and characterize successful strategies in maintaining significant weight loss over a 5 -year period. Very-lowcalorie diets produce a more rapid weight loss but should only be used for fewer than 16 weeks because of clinical adverse effects. Diets that are severely restricted in carbohydrates (3\%-10\% of total energy intake) and do not emphasize a reduction of energy intake may be effective in reducing weight in the short term, but there is no evidence that they are sustainable or innocuous in the long term because their high saturated-fat content may be atherogenic. Fat restriction in a weight-loss regimen is beneficial, but the optimal percentage has yet to be determined. Longitudinal trials are needed to resolve these issues. In this article I discuss the evidence for and pitfalls of various types of weight-loss diets and identify issues that physicians need to address in weight loss and weight-loss maintenance.

CMAJ 2006;174(I):56-63

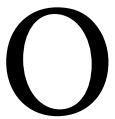
verweight and obesity are global problems affecting over one billion adults and 17.6 million children under 5 years of age. ${ }^{1-4}$ Since $1980,3^{-}$ fold increases in obesity have been reported in North America, the United Kingdom, Eastern Europe, the Middle East, the Pacific Islands, Australia and China. ${ }^{2}$ In Canada, about $48 \%$ of adults, or II. 5 million people, are overweight or obese. ${ }^{3}$ In North America, about two-thirds of obese adults are trying to lose weight. ${ }^{5,6}$ Unfortunately, success rates are low and range from $2 \%$ to $20 \% .^{7}$ Given the burden of disease associated with obesity, treatment is crucial for reducing secondary risks. Patients often consult their physicians about diet, yet many physicians are unfamiliar with the evidence for the use of various weight-loss regimens. The purpose of this article is to review and assess types of diets commonly recommended for weight reduction, with particular attention to lowcalorie and low-carbohydrate diets.

\section{Weight-loss goals}

The US National Institutes of Health recommends weight loss for overweight people (defined as having a body mass index of $25-29 \mathrm{~kg} / \mathrm{m}^{2}$ ) with a high waist circumference or with 2 or more risk factors for cardiovascular disease and other comorbidities. ${ }^{8}$ The position of the US Preventive Services Task Force ${ }^{9}$ is that clinicians should screen all adult patients for obesity and offer intensive counselling and behavioural intervention to promote sustained weight loss. The Canadian Task Force on Preventive Health Care ${ }^{10}$ recommends weight reduction for adults with a body mass index greater than $27 \mathrm{~kg} / \mathrm{m}^{2}$ and at least one obesity-related disease. The National Institutes of Health suggests a reduction of $10 \%$ in body weight as an initial goal. ${ }^{11} \mathrm{~A}$ weight loss of $5 \%-10 \%$ has been shown to reduce the risk of heart disease and stroke. ${ }^{12}$

Which diets result in safe weight loss, have positive longterm consequences for chronic disease risk factors, and are sustainable in the long term? This question has been only partially answered. Comparing dietary trials is difficult for several reasons: diet compositions vary in the amount and type of carbohydrates and fats, amount of protein, and degree that energy intake is restricted, all of which have intricate bearings on weight regulation; diets have specific actions on appetite and food preference that affect drop-out rates; study populations may have different associated diseases that modify outcomes; and the choice of statistical analyses can bias results. ${ }^{13}$

\section{Low-calorie diets}

In general, low-calorie diets are high in carbohydrates $(55 \%-60 \%$ of total daily energy intake), low in fat $(<30 \%$ of energy intake), and energy-reduced (deficit of $2100-$ $4200 \mathrm{~kJ} / \mathrm{d}$ : minimum of $4200-5040 \mathrm{~kJ} / \mathrm{d}$ for women and $5040-5880 \mathrm{~kJ} / \mathrm{d}$ for men). ${ }^{14}$ (See Box I for kilojoule-calorie conversions.) Diets in this category include the National Cholesterol Education Program (NCEP) Step I Diet with energy intake restriction; ${ }^{15}$ the DASH diet, ${ }^{16}$ which is based on the US Department of Agriculture Food Guide Pyramid; and some commercial programs (e.g., Weight Watchers).$^{14}$ Low-calorie diets should be high in fibre and have a low glycemic index. The glycemic index, a concept introduced by D.J. Jenkins to 
classify foods containing carbohydrates, represents the blood glucose response (incremental area under the curve) to a food portion containing $50 \mathrm{~g}$ of available carbohydrate compared with the response to an equivalent amount of either glucose or white bread. ${ }^{17}$ High-fibre and low-glycemic-index diets are associated with increased satiety, lower postprandial glycemic response and lower insulin levels. ${ }^{17-20}$ Postprandial hyperglycemia has been found to increase the risk of cardiovascular disease and diabetes. ${ }^{20-22}$

\section{Evidence}

The National Institutes of Health reviewed 34 randomized controlled trials to assess the effectiveness of low-calorie diets for lowering body weight, decreasing abdominal fat and improving cardiorespiratory fitness. ${ }^{8}$ The review concluded that low-calorie diets can lower total body weight by an average of about $8 \%$ during a period of $3-12$ months (evidence category A). Weight-loss and weight-loss maintenance interventions lasting 3-4.5 years (4 studies only) resulted in an average weight loss of $4 \%$, well below the definition proposed for successful weight loss (a decrease in 10\% of body weight sustained for more than I year). ${ }^{7}$ Low-calorie diets resulting in weight loss also lower the amount of abdominal fat, as shown by a reduction in waist circumference of $1.5-9.5 \mathrm{~cm}$ (evidence category A). The National Institutes of Health review also concluded that low-calorie diets alone do not improve cardiorespiratory fitness as measured by maximum rate of oxygen consumption (evidence category B), ${ }^{8}$ which reinforces the importance of combining diet and exercise programs in weight-loss interventions. Behaviour therapy in conjunction with dietary interventions (including low-calorie diets) has been shown to result in additional weight loss in the short term (I year) but not in the long term ( $3-5$ years) (evidence category B). ${ }^{8}$

There is a debate regarding the effectiveness of low-fat diets in weight reduction. ${ }^{23-28}$ Astrup and colleagues ${ }^{26}$ conducted a meta-analysis of $\mathrm{I} 6$ trials of 2-I2 months' duration, of which 14 were randomized. They reported that low-fat diets without intentional restriction of energy intake resulted in greater weight loss $(3.2 \mathrm{~kg}, 95 \%$ confidence interval I. $9-4.5 \mathrm{~kg}, p<0.00 \mathrm{I})$ than did habitual, or medium-fat, diets ad libitum. Weight loss was more substantial in heavier subjects. The authors concluded that, although the weight loss was small, the fact that it was achieved with a reduction in dietary fat and no planned reduction in energy intake may be of interest from a public health perspective. Similarly, Bray and Popkin $^{27}$ and Yu-Poth and colleagues ${ }^{15}$ found that decreases in fat intake were associated with weight loss. In a metaanalysis by $\mathrm{Yu}$-Poth and associates of 37 studies that used the NCEP Step I and Step II diets, every I\% decrease in energy from total fat was associated with a 0.28 - $\mathrm{kg}$ decrease in body weight $\left(R^{2}=0.57, p<0.0001\right) .{ }^{15}$ On the other hand, in a meta-analysis of 6 randomized controlled trials specifically targeting weight loss, ${ }^{23}$ Pirozzo and associates found no significant differences in the effects of low-fat diets and other weight-loss diets on obese and overweight subjects at $6, \mathrm{I} 2$ or 18 months. The overall weight loss between $\mathrm{I} 2$ and $\mathrm{I} 8$ months was only $2-4 \mathrm{~kg}$ in all studies. The National Institutes of Health review ${ }^{8}$ also concluded that lower-fat diets $(20 \%-30 \%$ of total energy intake) contribute to lower energy intake; there is little evidence that lowfat diets with no reduction in energy intake result in weight loss. ${ }^{8,29-31}$ This point is illustrated in a study by Powell and associates ${ }^{29}$ involving obese women, which compared the outcomes of a diet with a total of $5040 \mathrm{~kJ}$ per day but 4 different fat contents: 10\%, $20 \%, 30 \%$ and $40 \%$. No significant differences in weight loss were found $(-4.5 \mathrm{~kg}$, $-6.8 \mathrm{~kg},-6.9 \mathrm{~kg},-6.8 \mathrm{~kg}$, respectively) after the 3 -month intervention.

The NCEP Step I and II diets have been extensively studied and found to reduce circulating low-density lipoprotein cholesterol levels by ${ }_{12} \%$ and $\mathrm{I} 6 \%$ respectively. ${ }^{15}$ They have also been found to increase triglyceride levels, although not consistently. ${ }^{15,32}$ Increases in triglyceride levels have been ascribed to the high levels of postprandial glucose and insulin caused by the relatively high amount of carbohydrates in such diets. ${ }^{32}$ Higher triglyceride levels are usually associated with lower high-density lipoprotein cholesterol levels and with small low-density lipoprotein cholesterol particles that are more susceptible to oxidation; this metabolic profile is atherogenic. ${ }^{33-35}$ The potential negative effects of high-carbohydrate diets on triglyceride and high-density lipoprotein cholesterol levels may be attenuated if monounsaturated fats replace carbohydrates ${ }^{12,32,36}$ or if the diets are high in fibre and have a low glycemic index, ${ }^{12,37-40}$ although this remains controversial in the treatment of obesity. ${ }^{41,42}$

The 200I NCEP revised guidelines recommend the Therapeutic Lifestyle Change Diet for reducing the risk of coronary artery disease. ${ }^{36}$ On this diet, less than $7 \%$ of the total daily energy intake comes from saturated fat and $25 \%-35 \%$ comes from total fat. The diet is intended to reduce low-density lipoprotein cholesterol and triglyceride levels and increase high-density lipoprotein cholesterol levels. ${ }^{36}$ The revised Dietary Guidelines for Americans, released in 2005, recommend that less than Io\% of the daily energy intake come from saturated fat and $20 \%-35 \%$ from total fat, an increase in total fat from previous recommendations. ${ }^{43}$ Diets higher in total fat and consisting primarily of monounsaturated fatty acids are close to the Mediterranean style diet, where olive oil represents more than half of the fat intake. ${ }^{44}$ The Nutrition Recommendations for Canadians are currently under revision. ${ }^{45}$

Overall, low-calorie diets are a safe strategy for weight loss. A sample 5040-kJ diet plan based on Canada's Food Guide to Healthy Eating is outlined in the online appendix 
(available at www.cmaj.ca/cgi/content/full/174/I/56/DCI). A sedentary woman 45 years of age with a body mass index of 3I kg/m² (height I67.6 cm [5'6"], weight $87.5 \mathrm{~kg}$ [192.5 pounds]) and an energy requirement of $7988 \mathrm{~kJ}$ per day (calculated using the Harris-Benedict equation) can achieve a body mass index of about $26 \mathrm{~kg} / \mathrm{m}^{2}$ after 6 months on a $5040-\mathrm{kJ} / \mathrm{d}$ low-calorie diet. Physicians need to alert patients to the importance of portion sizes in the diet plan because people have a tendency to underestimate portion sizes, and portion sizes in restaurants and fast-food outlets are usually larger than those in the diet plan. Poor estimation of portion sizes can result in higher energy intake than the prescribed $5040 \mathrm{~kJ}$. In addition, physicians should advise patients to choose high-fibre and low-glycemic-index foods ${ }^{46}$ to assist in the control of hunger and to ensure a favourable serum lipid profile. Identifying emotional stimuli that trigger hunger or excessive food consumption may be warranted, along with strategies to deal with such episodes. Physical activity should be part of the weight-loss strategy.

\section{Low-carbohydrate diets}

Low-carbohydrate diets are relatively high in fat and protein content and are not recommended by the American Heart Association. ${ }^{47,48}$ Included in this category are the Protein Power diet and the Atkins diet. ${ }^{47-50}$

The Atkins diet has drawn the attention of consumers since its inception in the I970s. Atkins states that most people consume carbohydrates that are absorbed rapidly, which leads to increases in glycemia and insulin secretion. Lowered blood glucose levels and increased cravings result, whereby refined snack foods are usually consumed, which perpetuates the cycle and leads to body fat storage. ${ }^{49} \mathrm{~A}$ key premise of the Atkins diet is that the total energy intake is not important. Carbohydrate intake is severely restricted ( $3 \%-10 \%$ of total daily energy intake), whereas fat and protein can be consumed to satisfaction. ${ }^{49}$ Exercise is mandatory, and a daily vitamin, mineral and fatty acid supplement is recommended.

The metabolic principles of the Atkins $\operatorname{diet}^{51-53}$ need to be considered in relation to the diet strategy. When following a diet that limits carbohydrate intake to as little as $20 \mathrm{~g}$ per day in the induction phase, people end up reducing total energy intake because the choice of foods low in carbohydrates is limited; the resulting monotony of the diet has little appeal. The body depletes its glycogen stores, and gluconeogenesis is induced, whereby lean tissue is used to produce glucose as an energy source for the brain. Free fatty acids are also mobilized from adipose tissue, which results in ketone body formation. ${ }^{51}$ Mild ketosis decreases appetite, and the diet's high protein content increases satiety and activates thermogenesis. ${ }^{54-56}$

\section{Evidence}

In a review of 94 trials on the efficacy of low-carbohydrate diets from ig66 to 2003 , Bravata and colleagues ${ }^{57}$ reported that weight loss was principally associated with reduced energy intake and not reduced carbohydrate intake. These observations conform with the principles of thermodynamics. ${ }^{53}$ They are also in agreement with the results of 4 recent randomized trials designed to test the main principles of the Atkins diet, ${ }^{58-61}$ in which low-carbohydrate diets ( $<30 \mathrm{~g} / \mathrm{d}$ of carbohydrates, $<10 \%$ of total daily energy intake from carbohydrates, ad libitum protein and fat intake) were compared with the conventional low-fat, energyrestricted diet. Brehm and colleagues ${ }^{58}$ reported that the mean daily energy intake at the end of the 6-month study period was $5468 \mathrm{~kJ}$ on the low-carbohydrate diet and $5237 \mathrm{~kJ}$ on the low-calorie diet.

Both the low-calorie and low-carbohydrate diets result in weight loss..$^{58-61}$ Two studies, each 6 months in duration, reported greater weight loss with the low-carbohydrate diet than with the low-calorie diet. ${ }^{58,60}$ In a study by Brehm and colleagues ${ }^{58}$ subjects lost 8.5 (standard deviation [SD] I.o) $\mathrm{kg}$ on the low-carbohydrate diet compared with 3.9 (SD I.0) $\mathrm{kg}$ on the low-calorie diet $(p<0.00 \mathrm{r})$. Similarly, in a study by Yancy and associates ${ }^{60}$ the mean change in body weight was $-12.9 \%$ on the low-carbohydrate diet and $-6.7 \%$ on the lowcalorie diet $(p<0.001)$. The authors ${ }^{60}$ suggested that the greater weight loss seen with low-carbohydrate diet was possibly due to the increased thermic effect of the high protein content ${ }^{56}$ and to the energy loss in ketonuria. However, no relation could be established between weight loss and urinary or blood ketones. ${ }^{58,61}$ Postprandial thermogenesis is doubled on high-protein diets and contributes an additional loss of about $378 \mathrm{~kJ}$ per day. ${ }^{56}$ Unfortunately, physical activity was not assessed. Further research is required to determine the contribution of resting metabolic rate, energy expenditure during exercise, and thermogenesis toward weight loss and weight-loss maintenance on low-carbohydrate diets. In trials of longer duration, the greater initial weight loss on the low-carbohydrate diet was not maintained at I2 months. Foster and associates ${ }^{61}$ reported a weight change of -7.0 (SD 6.5) kg at 6 months on the low-carbohydrate diet compared with -3.2 (SD 5.6) $\mathrm{kg}$ on the low-calorie diet ( $p=$ 0.02 ), but no significant difference was observed at I 2 months $(-4.4$ [SD 6.7] kg with a low-carbohydrate diet $\mathrm{v}$. -2.5 [SD 6.3] kg with a low-calorie diet, $p=0.26$ ). Similarly, in a study by Stern and associates, ${ }^{59}$ weight change at one year was -5.I (SD 8.7) kg on a low-carbohydrate diet and -3.I (SD 8.4) kg on a low-calorie diet ( $p>0.05$ ).

Two studies assessed changes in body composition. Both Brehm and associates and Yancy and associates reported that weight loss resulted mainly from decreases in fat mass. ${ }^{58,60}$ However, they also observed losses of lean body mass that were significantly greater on the low-carbohydrate diet than on the low-calorie diet. Meckling and associates ${ }^{62}$ found that at the end of the Io-week study period, an energy-restricted low-carbohydrate diet was associated with a significant decrease in lean body mass (-I.9 kg) that was not observed in the low-fat diet group. For loss in body water, Yancy and associates reported that body water loss was greater on the lowcarbohydrate diet than on the low-calorie diet during the first 2 weeks of the study but was similar in both diet groups after 2 weeks. ${ }^{60}$ 
Overall, drop-out rates ranged from $20 \%$ to $40 \%$, with fewer people using the low-carbohydrate diet dropping out than those using the low-calorie diet. ${ }^{58-61}$

Greater decreases in triglyceride levels, a favourable outcome, were found with the low-carbohydrate diets than with the low-calorie diets at the end of both the 6-month and I2-month study periods. ${ }^{59-61}$ Foster and associates ${ }^{61}$ reported that triglyceride levels had decreased by $-28.1 \%$ (SD $23.6 \%$ ) on the low-carbohydrate diet and increased by $\mathrm{I} .4 \%$ (SD 52.5\%) on the low-calorie diet at the I-year follow-up. They also reported significant increases in low-density lipoprotein cholesterol levels at 3 months on the lowcarbohydrate diet compared with the low-calorie diet $(6.2 \%$ [SD 20.4\%] v. -II.I\% [SD I9.4\%] change, $p=0.005$ ). However, these differences disappeared at the I-year testing (0.5\% [SD 21.2\%] v. - $5.8 \%$ [SD I6.I\%] change, $p=0.47$ ), a result that was also observed in the other randomized trials. ${ }^{58-61}$ These results should not be interpreted as precluding the possibility of harm from low-carbohydrate diets through changes of serum lipid profile. In one study ${ }^{60}$ increases in low-density lipoprotein cholesterol levels of more than $10 \%$ were seen in $30 \%$ of subjects in the lowcarbohydrate diet group and only $\mathrm{I} 6 \%$ in the low-calorie diet group, and 2 participants using the low-carbohydrate diet were withdrawn from the trial because of important adverse effects on blood lipid levels. Furthermore, saturated-fat intake on low-carbohydrate diets is high ${ }^{58}$ representing $17 \%$ of total energy intake, which is almost double the current recommendations of major health organizations. ${ }^{12,18}$ Saturated fats are associated with increased levels of low-density lipoprotein cholesterol, a risk factor for coronary artery disease. ${ }^{12,15}$ Although the beneficial effects of low-carbohydrate diets on serum lipid levels may offset the negative effect of increased levels of saturated fat in the short term, ${ }^{63}$ the impact of the diet on low-density lipoprotein cholesterol levels over the long term ( $2-5$ years) must be evaluated. Furthermore, the effect of exercise and of vitamin and mineral supplementation associated with low-carbohydrate diets on lipid outcomes also needs to be assessed. Until these studies are conducted, a low-carbohydrate diet cannot be recommended for "lifetime maintenance," as Atkins states. ${ }^{49}$

Insulin sensitivity improved with both types of diets. ${ }^{58,61}$ Golay and associates ${ }^{31}$ compared 2 diets containing $4200 \mathrm{~kJ}$ per day, one composed of $32 \%$ protein, $15 \%$ carbohydrate and $53 \%$ fat and the other of $29 \%$ protein, $45 \%$ carbohydrate and $26 \%$ fat. They found that fasting plasma glucose, insulin, cholesterol and triglyceride levels were decreased in the lowcarbohydrate diet group $(p<0.0 \mathrm{I})$ and, to a lesser extent and less consistently, in the high-carbohydrate diet group, although weight losses were similar $(-8.3 \%$ [SD $0.5 \%$ ] v. $-7.4 \%$ [SD $0.6 \%]$ ).

Leptin levels were found to decrease equally in both the low-calorie diet and the low-carbohydrate diet groups at 3 months in the study by Brehm and colleagues. ${ }^{58}$ This may hamper weight-loss maintenance, since decreases in leptin levels in a negative energy balance stimulate food intake and energy storage to restore homeostasis. ${ }^{64-66}$
Nutrient analyses of low-carbohydrate diets by Freedman and associates ${ }^{14}$ and Anderson and associates ${ }^{67}$ show low amounts of vitamins $\mathrm{A}, \mathrm{B}_{6}$ and $\mathrm{E}$ and of folate, calcium, magnesium, iron, potassium and dietary fibre, which makes these diets nutritionally inadequate. Overall, low-carbohydrate diets are usually low in fruits and vegetables, dairy products and whole grains; these dietary patterns, if maintained over the long term, are associated with an increased risk of a variety of chronic diseases, including hypertension and cancer. ${ }^{12,16,68}$ High-protein diets affect renal function and can place greater demands on the kidney and liver for metabolizing and excreting excess urea and ammonia. ${ }^{47}$ They may be a health hazard for patients with renal or liver impaired functions in general, and for patients with diabetes in particular.

Overall, low-carbohydrate diets are not recommended. Their high protein and fat content is conducive to a high intake of saturated fat, as observed in clinical trials and nutrient analyses of the diet plan ${ }^{14,58,67}$ (see the online appendix). Although low-carbohydrate diets may not pose a serious health threat to a metabolically healthy obese patient in the short term, they may put people at risk of chronic diseases. Even if patients select monounsaturated fatty acids as their principal fat source, as with Mediterranean diets, the low-carbohydrate strategy does not restrict saturated-fat intake and is low in fruits, vegetables and dairy products, factors associated with increased risk of chronic diseases. Longitudinal studies to assess dietary patterns as well as chronic disease risk factors among people using low-carbohydrate diets for weight loss and weight-loss maintenance are needed.

\section{Very-low-calorie diets}

Very-low-calorie diets $(<3360 \mathrm{~kJ} / \mathrm{d})$ are protein-sparing modified fasts and consist of commercial preparations subject to government regulations ${ }^{69}$ or specific foods, including meat, fish and poultry. ${ }^{70-72}$ These diets need to contain proteins of high biologic value (high in essential amino acids) to preserve lean body mass, essential fatty acids, and vitamin and mineral supplements. They must be prescribed and patients using them monitored weekly by a physician to avoid severe negative nitrogen balance and electrolyte changes associated with starvation. ${ }^{71}$

Very-low-calorie diets are restricted to people with a body mass index over $30 \mathrm{~kg} / \mathrm{m}^{2}$, who face major health risks, and for whom other approaches have failed. ${ }^{70,71}$ Verylow-calorie diets result in an average weekly weight loss of I.5-2.5 kg, compared with $0.4^{-0.5} \mathrm{~kg}$ with low-calorie diets. ${ }^{72}$ The average weight loss at $12-16$ weeks on very-lowcalorie diets is about $20 \mathrm{~kg}$, compared with $8 \mathrm{~kg}$ on lowcalorie diets. ${ }^{8,72}$ Use of very-low-calorie diets does not improve weight-loss maintenance; ${ }^{8}$ however, there is some disagreement on this issue. ${ }^{73,74}$ Very-low-calorie diets are not recommended beyond 16 weeks, when low-calorie diets should be initiated to assist the patient in returning to a normal eating pattern.

Very-low-calorie diets are associated with a variety of side effects and with numerous complications, such as cholelithiasis, loss of lean body mass, ketosis and increased serum uric 
acid concentrations due to severe negative energy balance. ${ }^{71}$ Sudden death can occur, rarely, in vulnerable patients with comorbidities, especially if the energy intake is less than $2520 \mathrm{~kJ}$ per day. ${ }^{75}$ Sudden deaths resulting from very-lowcalorie diets in the I970s were attributed to the poor quality of dietary protein; an inadequate supply of electrolytes, vitamins and minerals; and extended use without adequate medical supervision. $^{73,75}$

Physicians can refer patients to a registered dietitian to receive a diet plan, or patients may consume commercial diet products (e.g., sachets), which are available on prescription. These formulations should not be confused with meal replacement products, which can be part of low-calorie diets. Low-calorie diets that use a meal replacement strategy (I or 2 meals substituted with a commercial fortified product containing about $840 \mathrm{~kJ}$ ) induced greater weight loss at I year (about $7 \%-8 \%$ of body weight) com- pared with the traditional low-calorie diets without meal replacements $\left(3 \%-7 \%\right.$ of body weight). ${ }^{76}$ Meal replacements and very-low-calorie diets can assist patients control energy intake by reducing the need to make decisions about food portion size. ${ }^{70}$

Overall, very-low-calorie diets present a number of medical risks but offer rapid weight loss. Intensive monitoring is required on the part of the physician, and patients must learn to maintain their weight loss when returning to normal eating patterns.

\section{Very-low-fat diets}

Many of the very-low-fat diets, which contain about I0\%-15\% total fat, were originally designed to prevent or reverse heart disease. ${ }^{14}$ Two of the most well-known very-low-fat diets, which are now promoted for weight loss, are the Ornish and

Table 1: Characteristics of weight-loss diets

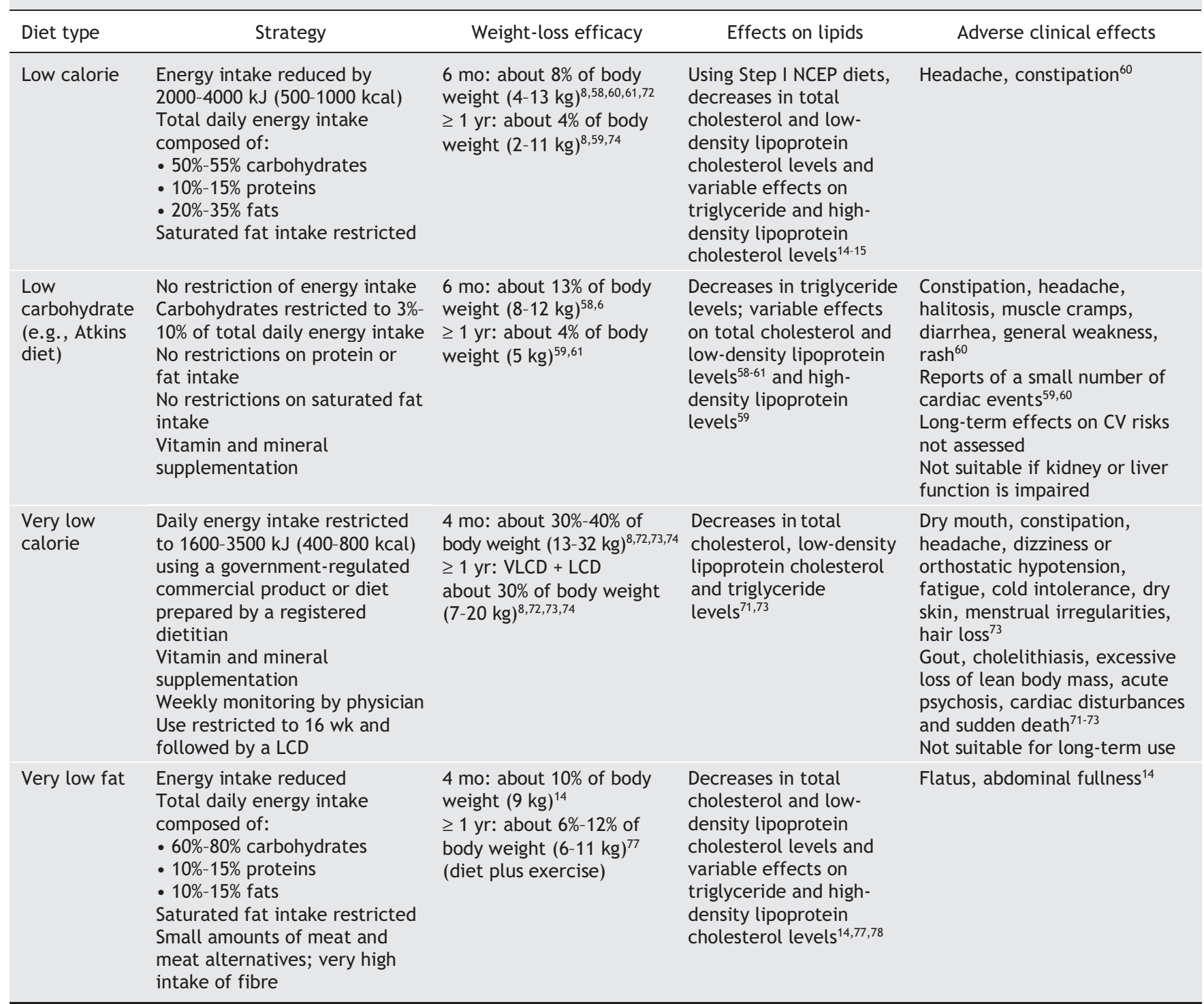


Pritikin programs. In the Lifestyle Heart Trial, Ornish and associates $^{77}$ reported that their intensive lifestyle changes program, consisting of a vegetarian diet with less than $10 \%$ fat, aerobic exercise, stress management, smoking cessation, and group support, resulted in a weight loss of $10.9 \mathrm{~kg}$ in year I and $5.8 \mathrm{~kg}$ in year 5 among subjects with moderate or severe coronary artery disease who were not taking lipid-lowering drugs. Coronary atherosclerosis regressed in the intervention group (relative improvement of $4.5 \%$ at year $\mathrm{I}$ and $7.9 \%$ at year 5) while it continued to progress (relative worsening of $5.4 \%$ at year I and $27.7 \%$ at year 5$)$ in the group receiving usual care ( $p<0.05$ between groups). Twice as many cardiac events occurred in the control group (2.25 v. 0.89 events/ patient) during the 5 -year follow-up. The independent effect of the diet in the Ornish study cannot be determined since it was associated with other weight-loss strategies. Unlike the Ornish vegetarian approach, the Pritikin program allows limited amounts of animal protein. ${ }^{14}$

Very-low-fat diets have a very high carbohydrate and fibre content. The American Heart Association ${ }^{78}$ cautions against the use of such diets because their high carbohydrate content can increase triglyceride levels. In addition, the diets can contain over twice (40-70 g/d) the recommended amount of fibre ${ }^{14,18,67}$ high fibre intakes can decrease the absorption of zinc, calcium and iron. ${ }^{55}$ Complaints of abdominal fullness have also been reported. ${ }^{14}$

Overall, very-low-fat diets offer a vegetarian-style weightloss regimen with low amounts of meat and alternates (see the online appendix), but their use should be monitored for their impact on plasma triglyceride levels and for nutrient adequacy.

\section{Diet characteristics and sustainability}

A summary of the characteristics of the various types of diets in terms of strategy, efficacy and effects are outlined in Table I. Low-calorie diets are the closest to most people's general eating patterns and present the fewest risks for the patient. The energy content of weight-loss maintenance diets should take into account the lower resting metabolic rate and decreased energy requirements due to body mass loss during weight loss. ${ }^{79,80}$

We still have no definitive answer as to which diets sustain long-term weight loss. The National Weight Control Registry in the United States provides useful information regarding successful weight-loss maintenance strategies. ${ }^{81}$ This registry includes people who have lost more than $\mathrm{I}_{3} \mathrm{~kg}$ of body weight and successfully maintained that weight loss for over 5 years. Over 4000 people are in the registry. The dietary pattern generally shared among participants included low amounts of fat (about $24 \%$ of the total daily energy intake), high amounts of carbohydrate, and a low energy intake $(5460-6300 \mathrm{~kJ} / \mathrm{d})$. Most eat breakfast daily, self-monitor weight and are physically active. Other studies report similar strategies for successful weight-loss maintenance, such as monitoring food portion sizes, energy and fat intake, and body weight, and avoiding the use of food to regulate mood. ${ }^{7,82,83}$

\section{Conclusion}

Safe choices for weight-loss regimens include energyrestricted diets calculated according to the Therapeutic Lifestyle Change Diet recommended by the National Cholesterol Education Program, ${ }^{36,84}$ the diet recommended by the Heart Association, ${ }^{85,86}$ the diet recommended by the Canadian Diabetes Association, ${ }^{87}$ and Canada's Food Guide to Healthy Eating. ${ }^{88}$ Low-carbohydrate diets and diets high in saturated fat are not recommended. Nutrition therapy in weight management should ensure that diets are safe and that they avoid causing high levels of postprandial glucose and lipid serum concentrations, induce optimal serum lipid composition to prevent coronary artery disease, do not increase the risk of hypertension or cancer, contain adequate nutrient intake and sustain weight loss. Long-term multicentre randomized intervention trials are needed to improve knowledge on these issues and to determine the contribution of diet, exercise, and metabolic and psychosocial factors to weight loss and weight-loss maintenance.

A concerted effort on the part of consumers, medical professionals, research funding agencies, food industry, community leaders, government legislators and nutrition policymakers is needed to fight obesity. ${ }^{68,89}$ With all of the intrinsic problems of weight-loss interventions, preventive measures should be given a distinct priority.

This article has been peer reviewed.

From the Department of Nutrition, Faculty of Medicine, and the Research Centre of Notre-Dame Hospital, Centre hospitalier de l'Université de Montréal, Université de Montréal

Competing interests: None declared.

Acknowledgements: I thank the Institute of Gender and Health, Canadian Institutes of Health Research, and Alain Ishac, MSc, RD, research dietitian at Notre-Dame Hospital of the Centre hospitalier de l'Université de Montréal, for preparing and analyzing the weight loss dietary plans presented in this review.

\section{REFERENCES}

I. World Health Organization. Global strategy on diet, physical activity and health. Obesity and overweight. 2004. Available: www.who.int/dietphysicalactivity/media len/gsfs_obesity.pdf (accessed 2005 Nov r6).

2. James PT, Leach R, Kalamara E, et al. The worldwide obesity epidemic. Obes Res 2001;9(Suppl 4):228S-33S.

3. Statistics Canada. Body Mass Index (BMI), by age group and sex, Canada, 2003. Health Indicators - June 2004 (Vol 2004, No I); Statistics Canada, Catalogue No 82-22I. Available: www.statcan.ca/english/freepub/82-22I-XIE/0o6o4/hlthstatus / conditionsi.htm (accessed 2005 Nov I6).

4. Flegal KM, Carroll MD, Ogden CI, et al. Prevalence and trends in obesity among US adults. JAMA 2002;288:1723-7.

5. Green KL, Cameron R, Polivy J, et al. Canadian Heart Health Surveys Research Group. Weight dissatisfaction and weight loss attempts among Canadian adults. CMAJ I997; I57(Suppl I):SI7-25.

6. Serdula MK, Mokdad AH, Williamson DF, et al. Prevalence of attempting weight loss and strategies for controlling weight. JAMA I999;282:1353-8.

7. Wing RR, Hill JO. Successful weight loss maintenance. Annu Rev Nutr 200I;2I: 323-4I.

8. National Heart, Lung and Blood Institute. Clinical guidelines on the identification, evaluation, and treatment of overweight and obesity in adults. The evidence report. NIH Publication No. 98-4083; I998 September.

9. US Preventive Services Task Force. Screening for obesity in adults. December 2003. Available: www.ahrq.gov/clinic/uspstf/uspsobes.htm (accessed 2005 Nov I6).

Io. Douketis JD, Feightner JW, Attia J, with the Canadian Task Force on Preventive Health Care. Periodic health examination, I999 update: I. Detection, prevention and treatment of obesity. $C M A J$ I999; $600: 513-25$. 
II. Executive summary of the clinical guidelines on the identification, evaluation, and treatment of overweight and obesity in adults: The National Heart, Lung, and Blood Institute expert panel on the identification, evaluation, and treatment of overweight and obesity in adults. Arch Intern Med I998;158:1855-67.

12. Krauss RM, Eckel RH, Howard B, et al. AHA Dietary Guidelines: revision 2000: A statement for healthcare professionals from the nutrition committee of the American Heart Association. Circulation 2000;102:2284-99.

13. Ware JH. Interpreting incomplete data in studies of diet and weight loss. $N$ Engl Med 2003;348:2136-7.

I4. Freedman MR, King J, Kennedy E. Popular diets: a scientific review. Obes Res 200I;9(Suppl I):IS-40S.

I5. Yu-Poth S, Zhao G, Etherton T, et al. Effects of the National Cholesterol Education Program's Step I and Step II dietary intervention programs on cardiovascular disease risk factors: a meta-analysis. Am J Clin Nutr 1999;69:632-46.

I6. Miller ER, Erlinger TP, Young DR, et al. Results of the Diet, Exercise, and Weight Loss Intervention Trial (DEW-IT). Hypertension 2002;40:612-8.

I7. Pawlak DB, Ebbeling CB, Ludwig DS. Should obese patients be counselled to follow a low-glycemic index diet? Yes. Obes Rev 2002;3:235-43.

I8. Canadian Diabetes Association Clinical Practice Guidelines Expert Committee Nutrition therapy. Can J Diabet 2003;27(Suppl 2):S27-3I.

I9. Ludwig DS. The glycemic index: physiological mechanisms relating to obesity, diabetes, and cardiovascular disease. JAMA 2002;287:24I4-23.

20. Brand-Miller J. Glycemic load and chronic disease. Nutr Rev 2003;6r:S49-55.

2I. Balkau B, Shipley M, Jarrette RJ, et al. High blood glucose concentration is a risk factor for mortality in middle-aged nondiabetic men. Diabetes Care 1998;21:360-7

22. The DECODE study group. European Diabetes Epidemiology Group. Glucose tolerance and mortality: comparison of WHO and American Diabetes Association diagnostic criteria. Lancet I999;354:6I7-2I.

23. Pirozzo S, Summerbell C, Cameron C, et al. Should we recommend low-fat diets for obesity? Obes Rev 2003;4:83-00.

24. Willett WC, Leibel R. Dietary fat is not a major determinant of body fat. Am J Med 2002;113:47S-59S.

25. Astrup A. The role of dietary fat in the prevention and treatment of obesity. Efficacy and safety of low-fat diets. Int J Obes Relat Metab Disord 200I;25 Suppl I:S46-50.

26. Astrup A, Grunwald GK, Melanson EL, et al. The role of low-fat diets in body weight control: a meta-analysis of ad libitum dietary intervention studies. Int J Obes Relat Metab Disord 2000;24:1545-52.

27. Bray GA, Popkin BM. Dietary fat intake does affect obesity. Am J Clin Nutr 1998;68: II $57-73$.

28. Ravussin E, Tataranni PA. Dietary fat and human obesity. J Am Diet Assoc 1997;97 (Suppl):S42-6.

29. Powell JJ, Tucker L, Fisher AG, et al. The effects of different percentages of dietary fat intake, exercise, and caloric restriction on body composition and body weight in obese females. Am J Health Promot I994;8:442-8.

30. Golay A, Eigenheer C, Morel Y, et al. Weight-loss with low or high carbohydrate diet? Int J Obes Relat Metab Disord 1996;20:1067-72.

3I. Golay A, Allaz A-F, Morel Y, et al. Similar weight loss with low- or high-carbohydrate diets. Am J Clin Nutr 1996;63:174-8.

32. Parks EJ, Hellerstein MK. Carbohydrate-induced hypertriacylglycerolemia: historica perspective and review of biological mechanisms. Am J Clin Nutr 2000;71:4I2-33.

33. Hokanson JE, Austin MA. Plasma triglyceride level is a risk factor for cardiovascular disease independent of high-density lipoprotein cholesterol level: a meta-analysis of population-based prospective studies. J Cardiovasc Risk 1996;3:213-9.

34. Stampfer MJ, Krauss RM, Ma J, et al. A prospective study of triglyceride level, lowdensity lipoprotein particle diameter, and risk of myocardial infarction. JAMA I996;276:882-8.

35. Austin MA, Hokanson JE. Epidemiology of triglycerides, small dense low-density lipoprotein, and lipoprotein(a) as risk factors for coronary heart disease. Lipid Disord Med Clin North Am 1994;78:99-II5.

36. Third report of the National Cholesterol Education Program (NCEP) Expert Panel Detection, evaluation and treatment of high blood cholesterol in adults (adul treatment panel III). Executive summary. NIH Publication No. oI-3670; 200I May. Available: www.nhlbi.nih.gov/guidelines/cholesterol/atp3xsum.pdf (accessed 2005 Nov I5).

37. Anderson JW, Zeigler JA, Deakins DA, et al. Metabolic effects of high-carbohydrate, high-fiber diets for insulin-dependent diabetic individuals. Am J Clin Nutr I991;54:936-43.

38. Wolever TM, Mehling C. High-carbohydrate-low-glycaemic index dietary advice improves glucose disposition index in subjects with impaired glucose tolerance. $B$ J Nutr 2002;87:477-87.

39. Giacco R, Parillo M, Rivellese AA, et al. Long-term dietary treatment with increased amounts of fiber-rich low-glycemic index natural foods improves blood glucose control and reduces the number of hypoglycemic events in type I diabetic patients. Diabetes Care 2000;23:146I-6.

40. American Diabetes Association. Nutrition principles and recommendations in diabetes. Diabetes Care 2004;27(Suppl I):S36-46.

4I. Astrup A. The role of the glycemic index of foods in body weight regulation and obesity. Is more evidence needed? Obes Rev 2002;3:233

42. Raben A. Should obese patients be counselled to follow a low-glycemic index diet? No. Obes Rev 2002;3:245-56.

43. 2005 Report of the dietary guidelines advisory committee. Part A: Executive sumary. Available: www.health.gov/dietaryguidelines/dga2005/report/PDF/A_ExecSummary .pdf (accessed 2005 Nov I5).

44. American Heart Association. Mediterranean diet. What is the "Mediterranean' diet? Available: www.americanheart.org/presenter.jhtml?identifier $=4644$ (accessed 2005 Nov I5).

45. Health Canada. Food and nutrition. Nutrition policies and dietary guidance in Canada. Available: www.hc-sc.gc.ca/fn-an/nutrition/diet-guide-nutri/nut_pol_diet _guid-pol_nut_lig_direc_e.html (accessed 2005 Nov 15).

46. Canadian Diabetes Association. The glycemic index. Available: www.diabetes.ca /files/Diabetes_GL_FINAL2_CPGo3.pdf (accessed 2005 Nov I5).

47. St. Jeor ST, Howard BV, Prewitt E, et al.; AHA Nutrition Committee. AHA Science advisory. Dietary protein and weight reduction. A statement for healthcare professionals from the nutrition committee of the Council on nutrition, physical activity, and metabolism of the American Heart Association. Circulation 200I;104:I869-74.

48. Kappagoda CT, Hyson DA, Amsterdam EA. Low-carbohydrate-high-protein diets. Is there a place for them in clinical cardiology? J Am Coll Cardiol 2004;43:725-30.

49. Atkins RC. Dr. Atkins' New Diet Revolution. New York: HarperCollins Publishers; I999.

50. Atkins Health and Medical Information Services. The Atkins essentials. A two week program to jump-start your low carb lifestyle. New-York: Harper Collins Publishers; 2004.

5I. Westman EC. A review of very low carbohydrate diets for weight loss. J Clin Outcomes Manage I999;6:36-40.

52. Astrup A, Larsen TM, Harper A. Atkins and other low-carbohydrate diets: hoax or an effective tool for weight loss? Lancet 2004;364:897-9.

53. Bray GA. Low-carbohydrate diets and realities of weight loss. JAMA 2003;289: I853-5.

54. Hill AJ, Blundell JE. Macronutrients and satiety: the effects of a high-protein or high-carbohydrate meal on subjective motivation to eat and food preferences. Nutr Behav I986;3:133-44.

55. Insel P, Turner RE, Ross D. Nutrition. Massachusetts: Jones and Bartlett Publishers; 2004.

56. Johnston CS, Day CS, Swan PD. Postprandial thermogenesis is increased $100 \%$ on a high-protein, low-fat diet versus a high-carbohydrate, low-fat diet in healthy, young women. J Am Coll Nutr 2002;2I:55-6r.

57. Bravata DM, Sanders L, Huang J, et al. Efficacy and safety of low-carbohydrate diets. A systematic review. JAMA 2003;289:1837-50.

58. Brehm BJ, Seeley RJ, Daniels S, et al. A randomized trial comparing a very low carbohydrate diet and a calorie-restricted low fat diet on body weight and cardiovascular risk factors in healthy women. J Clin Endocrinol Metab 2003;88:1617-23.

59. Stern L, Iqbal N, Seshadri P, et al. The effects of low-carbohydrate versus conventional weight loss diets in severely obese adults: one-year follow-up of a randomized trial. Ann Intern Med 2004;140:778-85.

6o. Yancy WS, Olsen MK, Guyton JR, et al. A low-carbohydrate, ketogenic diet versus a low-fat diet to treat obesity and hyperlipidemia. Ann Intern Med 2004;140:769-77.

6r. Foster GD, Wyatt HR, Hill JO, et al. A randomized trial of a low-carbohydrate diet for obesity. NEngl JMed 2003;348:2082-9o.

62. Meckling KA, O'Sullivan C, Saari D. Comparison of a low-fat diet to a low-carbohydrate diet on weight loss, body composition, and risk factors for diabetes and cardiovascular disease in free-living, overweight men and women. J Clin Endocrinol Metab 2004;89:2717-23.

63. Willett WC. Reduced-carbohydrate diets: no roll in weight management? Ann Intern Med 2004;140:836-7.

64. Schwartz MW, Seeley RJ. The new biology of body weight regulation. JAm Diet As soc $1997 ; 97: 54-8$.

65. Woods SC, Seeley RJ, Porte D Jr, et al. Signal that regulate food intake and energy homeostasis. Science I998;280:1378-83.

66. Schwartz MW, Woods SC, Seeley RJ, et al. Is the energy homeostasis system inherently biased toward weight gain? Diabetes 2003;52:232-8.

67. Anderson JW, Konz EC, Jenkins DJA. Health advantages and disadvantages of weight-reducing diets: a computer analysis and critical review. J Am Coll Nutr 2000;19:578-90.

68. Eyre H, Kahn R, Robertson RM. ACS/ADA/AHA Scientific Statement. Preventing cancer, cardiovascular disease, and diabetes. A common agenda for the American Cancer Society, the American Diabetes Association, and the American Heart Association. Circulation 2004;I09:3244-55.

69. Health Canada. Food and Drug Regulations. Part B, Divisions 17-28, Articles B.24.300-B.24.304 (Foods represented for use in very low energy diets, p. 35-6 of PDF file), 2002 Dec I2. Available: www.hc-sc.gc.ca/fn-an/alt_formats/hpfb-dgpsa/pdf/legislation/e_d-text-2.pdf (accessed 2005 Nov I6).

70. Position of the American Dietetic Association. Weight management. J Am Diet As soc 2002; I02:II45-55.

7I. American Association of Clinical Endocrinologists (AACE) Obesity Statement. AACE/ACE position statement on the prevention, diagnosis, and treatment of obesity. Endocr Pract 1998;297-330.

72. National Task Force on the Prevention and Treatment of Obesity. Very low-calorie diets. JAMA I993;270:967-74.

73. Saris WHM. Very-low-calorie diets and sustained weight loss. Obes Res 2001;9 (Suppl 4):295S-30IS.

74. Anderson JW, Konz EC, Frederich RC, et al. Long-term weight-loss maintenance: a meta-analysis of US studies. Am J Clin Nutr 200I;74:579-84.

75. Dwyer JT, Melanson KJ. Dietary treatment of obesity. 2002 Sept 24. Ch. I8 of Obesity, ed. JF Caro. Endotext.com. Available: www.endotext.org/obesity/obesityr $8 /$ obesityr8.htm (accessed 2005 Nov I6).

76. Heymsfield SB, van Mierlo CJ, van der Knaap HC, et al. Weight management using a meal replacement strategy: meta and pooling analysis from six studies. Int JObes 2003;27:537-49. 
77. Ornish D, Scherwitz LW, Billings JH, et al. Intensive lifestyle changes for reversal of coronary heart disease. JAMA I998;280:200I-7.

78. Lichtenstein AH, Van Horn L, for the AHA Nutrition Committee. AHA Science advisory. Very low fat diets. A statement for healthcare professionals from the nutrition committee of the Council on nutrition, physical activity, and metabolism of the American Heart Association. Circulation 1998;98:935-9.

79. Wyatt HR, Grunwald GK, Seagle HM, et al. Resting energy expenditure in reducedobese subjects in the National Weight Control Registry. Am J Clin Nutr 1999;69: II89-93.

8o. Weinsier RL, Nagy TR, Hunter GR, et al. Do adaptive changes in metabolic rate favor weight regain in weight-reduced individuals? An examination of the set-point theory. Am J Clin Nutr 2000;71:1088-94.

8r. Hill J, Wing R. The National Weight Control Registry. Available: http://xnet .kp.org/permanentejournal/sumo3/registry.pdf (accessed 2005 Nov I6).

82. Byrne S, Cooper Z, Fairburn C. Weight maintenance and relapse in obesity: a qualitative study. Int J Obes Relat Metab Disord 2003;7:955-62.

83. Sherwood NE, Jeffery RW, French SA, et al. Predictors of weight gain in the Pound of Prevention Study. Int J Obes Relat Metab Disord 2000;24:395-403.

84. National Heart, Blood, and Lung Institute. National Cholesterol Education Program. Third report of the expert panel on detection, evaluation, and treatment of high blood cholesterol in adults (Adult Treatment Panel III). Available: www.nhlbi.nih.gov/guidelines/cholesterol/ (accessed 2005 Nov 17). [Practical information for patients based on the ATP II guidelines is found in appendices B-F
The practical guide. Identification, evaluation, and treatment of overweight and obesity in adults. NIH publication no.00-4084; 2000 October. Available: www.nhlbi.nih.gov/guidelines/obesity/prctgd_c.pdf (accessed 2005 Nov I7).]

85. Heart and Stroke Foundation of Canada. BP info: Treatment \& control - dietary changes. Available: wwr.heartandstroke.ca/Page.asp?PageID =I6I3\&ContentID=I0400\&ContentTypeID=I (accessed 2005 Nov I7).

86. National Heart, Blood, and Lung Institute. Facts about the DASH eating plan. Available: www.nhlbi.nih.gov/health/public/heart/hbp/dash/new_dash.pdf (accessed 2005 Nov I7).

87. Canadian Diabetes Association. Good Health Eating Guide/Food Choices Values. The revision of the Good Health Eating Guide. Available: www.diabetes.ca/Section_Professionals/ng_gheg.asp (accessed 2005 Nov I7).

88. Health Canada. Food and Nutrition. Canada's Food Guide to Healthy Eating. Available: www.hc-sc.gc.ca/hpfb-dgpsa/onpp-bppn/food_guide_rainbow_e.html (accessed 2005 Nov I7).

89. Strychar I. Fighting obesity: a call to arms. Can J Public Health 2004;95:12-5.

Correspondence to: Dr. Irene Strychar, Hôpital Notre-Dame du CHUM, I56o Sherbrooke est, Pavillon Mailloux, porte K-6244, Montréal QC H2L 4MI; fax 5I4 4I2-7603

\section{P HYSICIAN MA N A G E R I NSTITUTE}

\section{A five level credit progr am exclusively for physicians designed to develop superior leadership and management ski7ls}

Approved for RCPSC, CFPC, CCHSE credits

In-house PMII

A practical, cost effective and fooused training qpoortunity held on-site for medical leaders and managers

For information: tel 800 663-7336 or 613 731-8610 x2319 (BVI) or x2261 (In-house AMI) professional_development@cma.ca

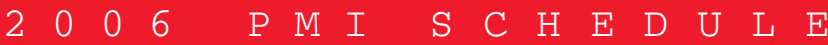

\section{BMI I/II}

Mar. 5-7/Mar . 8-10

Apr . 2-4/Apr . 57

Jine 11-13/June 14-16

Sept. 24-26/Sept. 27-29

Victoria, BC

Toronto, aN

Ottawa, ON

Calgary, AB

\section{$\mathrm{BMI}$ III/IV}

Apr. 30-May 2/May 3-5 Niagara-on-the-Lake, ON

Nov . 5-7/1 br . 8-10

\section{Vancouver, BC}

PIII V

cct. 20-22
Vancouver, BC

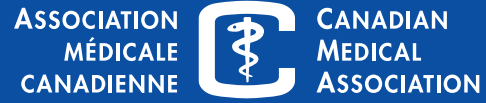

